\title{
A Test of Performance Comparison of Multifunctional High-speed Highway Condition Monitors
}

\author{
Chen Nan ${ }^{a}$,, Yu Yongyan ${ }^{b}$ and He Huayange ${ }^{c}$ \\ Research Institute of Highway, Ministry of Transport, Beijing 100086, China; \\ n.chen@rioh.cn, byy.yu@ rioh.cn, 'hy.he@ rioh.cn
}

\begin{abstract}
This paper is involed in a test of performance comparison of multifunctional high-speed highway condition monitors. Data of rut, IRI and crackings has been collected and analysis of variation coefficient and correlation has also been analyzed. A significant difference of all samples is revealed in the test. It is of great affection for operators, work condition to the result of the test. And a few of the samples even didn't finish some sections of the test. Above all, the result of the test can provide the department of maintenance very important information.
\end{abstract}

Keywords: pavement condition, laser, multifunctional high-speed highway condition monitors, correlation, rut, IRI, cracking.

\section{Introduction}

Multifunctional High-speed Highway Condition Monitor (MHHCM) is widely used for monitoring the condition of pavement in the world. The system of MHHCM is integrated of various instruments of high precision. The quality of data collected by MNNCM is very significant for a correct evaluation of pavement condition. It is of great necessary to evaluate performance of MHHCM for highway maintenance department. So a test of comparison has been arranged and 19 vehicles of MHHCM have been test as representative samples for different regions as well as different producers. And the difference among all MNNCM systems has been revealed in the test.

\section{Organization of the test}

The test was conducted in a section of road network (Fig.1) which is approximately 30km long, including $15 \mathrm{~km}$ of urban road and $15 \mathrm{~km}$ of rural road. The data of distance, location, pavement cracking, international roughness index (IRI), rut and pavement image have been collected for each MHHCM. The data collecting process is of extreme continuity and each intersection was also marked. All 19 vehicles must be driving along the same direction and the same lane of the test road. The collected data should be saved for different sections of the test road.

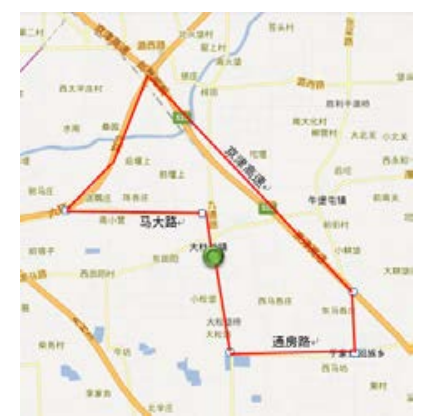

Fig. 1 the section of road network for the test 
In order to evaluating the performance of various MNNCM, the data collected from representative sections of the test road was analyzed. And the work of data analysis was conducted at the same location as well as the same time for all 19 MNNCM samples.

\section{Data analysis and evaluation}

\subsection{The evaluation index}

In order to evaluate the repetition of the test result, a variation coefficient index $\mathrm{C}_{\mathrm{v}}$ was used in analyzing the difference among all samples. In the following equations, $C_{v}$ is a variation coefficient index and $S_{D}$ is standard deviation and $\bar{X}$ is average of the data sample. A correlation analysis for each sample with others has been made to reveal the difference for all samples. By the way, each sample was randomly named by numbers.

$$
\begin{gathered}
C_{v}=\frac{S_{D}}{\bar{X}} \times 100 \% \\
S_{D}=\sqrt{\frac{1}{n-1} \sum_{i=1}^{n}\left(X_{i}-\bar{X}\right)^{2}}
\end{gathered}
$$

\subsection{Analysis of the rut}

The characteristic of rut data of both urban and rural road is show as follows. Each data is for 10m's rut, few of which may deviate from others. It is obviously seen in fig. 2 and fig. 3 that the data of rural road was of more fluctuation than urban road. Because the condition of rural road is more complicated than urban road. The variation coefficient of rural road samples is $7.78 \%$. The variation coefficient of urban road is $6.27 \%$. Both index is above $5 \%$ which is the creation of the standard.

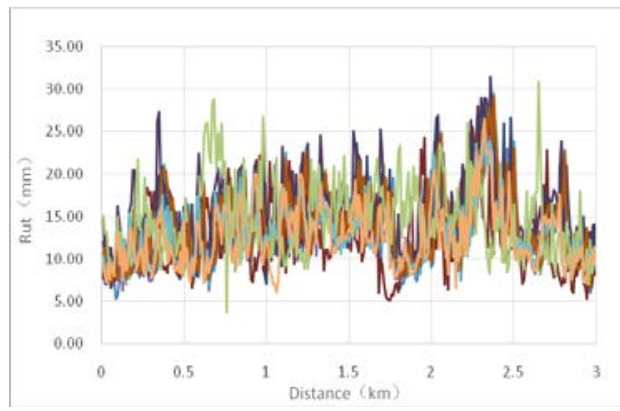

Fig. 2 rut data of urban road

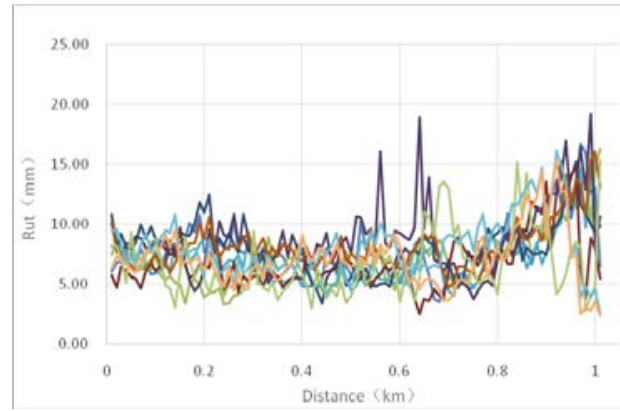

Fig. 3 rut data of rural road

A correlation analysis for each sample of urban road is calculated as Tab.1. It is shown that No.2431 is of good correlation with others and No.3124 and No.4132 is of bad correlation with others. In Tab.2, No.2341 is of good correlation and No.3124, No.3214 and No.4132 are of bad correlation for the rural road.

\begin{tabular}{|c|c|c|c|c|c|c|c|c|c|c|c|}
\hline $\begin{array}{c}\text { correlatio } \\
\mathrm{n}\end{array}$ & 1234 & 2134 & 2143 & 2341 & 2431 & 3124 & 3214 & 3412 & 4132 & 4231 & 4312 \\
\hline 1234 & 1 & 0.842 & 0.484 & 0.955 & 0.57 & 0.177 & 0.524 & 0.956 & 0.058 & 0.446 & 0.445 \\
\hline 2134 & 0.842 & 1 & 0.55 & 0.916 & 0.644 & 0.168 & 0.577 & 0.924 & 0.016 & 0.509 & 0.525 \\
\hline 2143 & 0.484 & 0.55 & 1 & 0.514 & 0.68 & 0.245 & 0.738 & 0.519 & -0.015 & 0.936 & 0.937 \\
\hline 2341 & 0.955 & 0.916 & 0.514 & 1 & 0.613 & 0.169 & 0.557 & 0.99 & 0.04 & 0.468 & 0.474 \\
\hline 2431 & 0.57 & 0.644 & 0.68 & 0.613 & 1 & 0.204 & 0.775 & 0.616 & -0.001 & 0.636 & 0.653 \\
\hline 3124 & 0.177 & 0.168 & 0.245 & 0.169 & 0.204 & 1 & 0.234 & 0.172 & 0.215 & 0.246 & 0.248 \\
\hline 3214 & 0.524 & 0.577 & 0.738 & 0.557 & 0.775 & 0.234 & 1 & 0.56 & 0 & 0.719 & 0.72 \\
\hline 3412 & 0.956 & 0.924 & 0.519 & 0.99 & 0.616 & 0.172 & 0.56 & 1 & 0.04 & 0.469 & 0.478 \\
\hline 4132 & 0.058 & 0.016 & -0.015 & 0.04 & -0.001 & 0.215 & 0 & 0.04 & 1 & -0.017 & -0.021 \\
\hline 4231 & 0.446 & 0.509 & 0.936 & 0.468 & 0.636 & 0.246 & 0.719 & 0.469 & -0.017 & 1 & 0.921 \\
\hline 4312 & 0.445 & 0.525 & 0.937 & 0.474 & 0.653 & 0.248 & 0.72 & 0.478 & -0.021 & 0.921 & 1 \\
\hline
\end{tabular}

Tab.1 correlation of samples of urban road 
Tab.2 correlation of samples of rural road

\begin{tabular}{c|c|c|c|c|c|c|c|c|c|c}
\hline correlation & 1234 & 2143 & 2341 & 2431 & 3124 & 3214 & 3412 & 4132 & 4231 & 4312 \\
\hline 1234 & 1 & 0.444 & 0.662 & 0.550 & 0.385 & 0.598 & 0.693 & -0.125 & 0.100 & 0.123 \\
\hline 2143 & 0.444 & 1 & 0.632 & 0.360 & 0.286 & 0.420 & 0.598 & 0.282 & 0.069 & 0.055 \\
\hline 2341 & 0.662 & 0.632 & 1 & 0.713 & 0.341 & 0.468 & 0.867 & 0.121 & -0.025 & -0.051 \\
\hline 2431 & 0.550 & 0.360 & 0.713 & 1 & 0.345 & 0.270 & 0.606 & 0.084 & 0.049 & 0.042 \\
\hline 3124 & 0.385 & 0.286 & 0.341 & 0.345 & 1 & 0.234 & 0.384 & 0.123 & 0.541 & 0.565 \\
\hline 3214 & 0.598 & 0.420 & 0.468 & 0.270 & 0.234 & 1 & 0.579 & 0.010 & 0.037 & 0.112 \\
\hline 3412 & 0.693 & 0.598 & 0.867 & 0.606 & 0.384 & 0.579 & 1 & 0.068 & -0.030 & 0.035 \\
\hline 4132 & -0.125 & 0.282 & 0.121 & 0.084 & 0.123 & 0.010 & 0.068 & 1 & 0.237 & 0.052 \\
\hline 4231 & 0.100 & 0.069 & -0.025 & 0.049 & 0.541 & 0.037 & -0.030 & 0.237 & 1 & 0.864 \\
\hline 4312 & 0.123 & 0.055 & -0.051 & 0.042 & 0.565 & 0.112 & 0.035 & 0.052 & 0.864 & 1 \\
\hline
\end{tabular}

\subsection{Analysis of the IRI}

The characteristic of IRI data of both urban and rural road is show as follows. Each data is for 100m's IRI, only few of which may deviate from others. It is obviously seen in fig.4 that the data was of more fluctuation from $2 \mathrm{~km}$ to $2.5 \mathrm{~km}$, which indicates a rough section of the test road. Most of the samples can reveal the same road condition. The variation coefficient of rural road samples is $9.25 \%$. The variation coefficient of urban road is $8.94 \%$. Both index is above $5 \%$ which is the creation of the standard. The big deviation may be caught by the difference of the encoders.

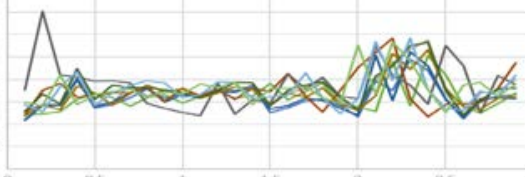

Fig. 4 IRI data of urban road

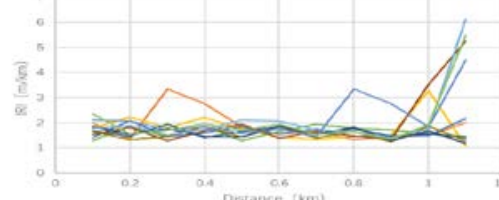

Fig.5 IRI data of rural road

A correlation analysis for each sample of urban road is calculated as Tab.3. It is shown that No.2134, No.2341, No.2431, No.3214, No.3412 and No.3421 are of good correlation with others. No.2413, No.3124, No.3142 and No.4312 are of bad correlation with others. In Tab.4, No.1234, No.2143 and No.2413 are of bad correlation with others. No.3124 and No.3421 are of good correlation. So we can see a big differentiation among all samples for the data of IRI.

Tab.3 correlation of samples of urban road

\begin{tabular}{|c|c|c|c|c|c|c|c|c|c|c|c|}
\hline $\begin{array}{c}\text { Correlatio } \\
\mathrm{n}\end{array}$ & 2134 & 2341 & 2413 & 2431 & 3124 & \multicolumn{2}{|r|}{3142} & 3214 & 3412 & 3421 & 4312 \\
\hline 2134 & 1 & 0.885 & 0.548 & 0.795 & 0.073 & \multicolumn{2}{|r|}{-0.070} & 0.871 & 0.950 & 0.610 & 0.200 \\
\hline 2341 & 0.885 & 1 & 0.277 & 0.932 & 0.018 & \multicolumn{2}{|r|}{-0.079} & 0.744 & 0.905 & 0.715 & 0.045 \\
\hline 2413 & 0.548 & 0.277 & 1 & 0.150 & 0.016 & \multicolumn{2}{|r|}{-0.121} & 0.741 & 0.498 & -0.028 & 0.123 \\
\hline 2431 & 0.795 & 0.932 & 0.150 & 1 & 0.070 & \multicolumn{2}{|r|}{0.018} & 0.608 & 0.831 & 0.795 & 0.027 \\
\hline 3124 & 0.073 & 0.018 & 0.016 & 0.070 & 1 & \multicolumn{2}{|r|}{0.216} & 0.107 & 0.039 & 0.327 & 0.512 \\
\hline 3142 & -0.070 & -0.079 & -0.121 & 0.018 & 0.216 & \multicolumn{2}{|r|}{1} & -0.095 & 0.013 & -0.028 & -0.217 \\
\hline 3214 & 0.871 & 0.744 & 0.741 & 0.608 & 0.107 & \multicolumn{2}{|r|}{-0.095} & 1 & 0.864 & 0.384 & 0.245 \\
\hline 3412 & 0.950 & 0.905 & 0.498 & 0.831 & 0.039 & & 0.013 & 0.864 & 1 & 0.616 & 0.132 \\
\hline 3421 & 0.610 & 0.715 & -0.028 & 0.795 & 0.327 & & -0.028 & 0.384 & 0.616 & 1 & 0.339 \\
\hline 4312 & 0.200 & 0.045 & 0.123 & 0.027 & 0.512 & & -0.217 & 0.245 & 0.132 & 0.339 & 1 \\
\hline & The co & tion was e & lated by $\mathrm{Pe}$ & son index, in & which 1 stand & for com & nplete correlat & ion and 0 stan & Is for non-co & lation. & \\
\hline & & & Tab. & correla & on of sal & mples & s of rural & road & & & \\
\hline $\begin{array}{c}\text { Correlatio } \\
\mathrm{n}\end{array}$ & 1234 & 2143 & 2341 & 2413 & 2431 & 3124 & 3214 & 3241 & 3421 & 4231 & 4312 \\
\hline 1234 & 1 & 0.003 & -0.171 & -0.281 & 0.253 & -0.075 & 0.066 & 0.003 & 0.023 & -0.185 & 0.124 \\
\hline 2143 & 0.003 & 1 & -0.210 & 0.010 & -0.174 & 0.070 & 0.482 & 0.220 & -0.380 & -0.432 & -0.321 \\
\hline 2341 & -0.171 & -0.210 & 1 & 0.076 & -0.523 & 0.663 & -0.557 & -0.643 & 0.674 & 0.343 & 0.532 \\
\hline 2413 & -0.281 & 0.010 & 0.076 & 1 & -0.322 & -0.255 & 0.039 & -0.072 & -0.279 & -0.084 & -0.349 \\
\hline 2431 & 0.253 & -0.174 & -0.523 & -0.322 & 1 & -0.476 & 0.243 & 0.754 & -0.358 & -0.317 & -0.325 \\
\hline 3124 & -0.075 & 0.070 & 0.563 & -0.255 & -0.476 & 1 & -0.133 & -0.509 & 0.867 & 0.616 & 0.859 \\
\hline 3214 & 0.066 & 0.482 & -0.557 & 0.039 & 0.243 & -0.133 & 1 & 0.635 & -0.310 & -0.340 & -0.188 \\
\hline 3241 & 0.003 & 0.220 & -0.643 & -0.072 & 0.754 & -0.509 & 0.635 & 1 & -0.552 & -0.429 & -0.452 \\
\hline 3421 & 0.023 & -0.380 & 0.674 & -0.279 & -0.358 & 0.867 & -0.310 & -0.552 & 1 & 0.746 & 0.973 \\
\hline 4231 & -0.185 & -0.432 & 0.343 & -0.084 & -0.317 & 0.616 & -0.340 & -0.429 & 0.746 & 1 & 0.739 \\
\hline 4312 & 0.124 & -0.321 & 0.532 & -0.349 & -0.325 & 0.859 & -0.188 & -0.452 & 0.973 & 0.739 & 1 \\
\hline
\end{tabular}




\subsection{Analysis of the Cracking}

The characteristic of Cracking data of both urban and rural road is show as follows. Each data is for $10 \mathrm{~m}$ 's Cracking. It is obviously seen in fig. 6 that the data was of much fluctuation from $2 \mathrm{~km}$ to $2.5 \mathrm{~km}$, which indicates a bad damage section of the test road. Most of the samples can reveal the same road condition. The variation coefficient of rural road samples is $11.73 \%$. The variation coefficient of urban road is $6.87 \%$. Both index is above $5 \%$ which is the creation of the standard.

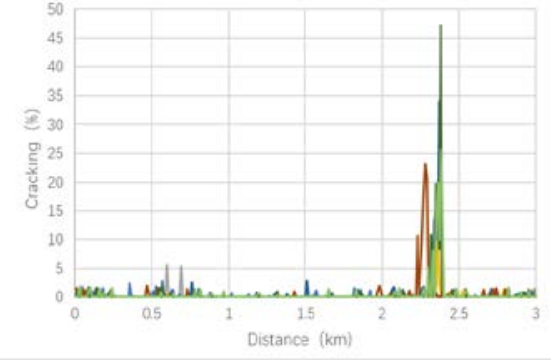

Fig. 6 Cracking data of urban road

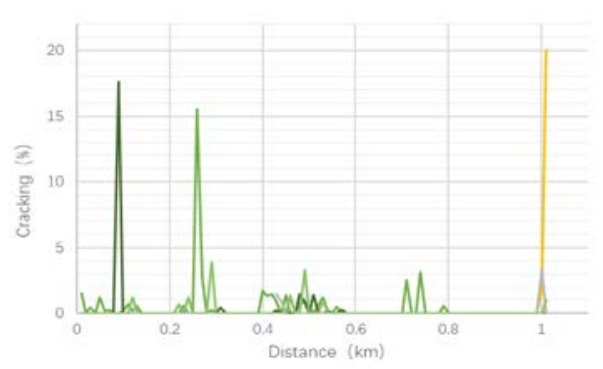

Fig.7 Cracking data of rural road

A correlation analysis for each sample of urban road is calculated as Tab.5. It is shown that No.2341, No.2431, No.3412, No.4312 are of good correlation with others. No.2134, No.2143, No.3124 are of bad correlation with others. In Tab.6, most samples are of bad correlation with others, which reveals a much complicated condition of rural raod.

Tab.5 correlation of samples of urban road

\begin{tabular}{|c|c|c|c|c|c|c|c|}
\hline Correlation & 2134 & 2143 & 2341 & 2431 & 3124 & 3412 & 4312 \\
\hline 2134 & 1 & -0.012 & 0.198 & -0.015 & 0.014 & 0.045 & 0.354 \\
\hline 2143 & -0.012 & 1 & 0.449 & 0.345 & -0.014 & 0.310 & 0.553 \\
\hline 2341 & 0.198 & 0.449 & 1 & 0.845 & 0.005 & 0.857 & 0.864 \\
\hline 2431 & -0.015 & 0.345 & 0.845 & 1 & -0.009 & 0.621 & 0.599 \\
\hline 3124 & 0.014 & -0.014 & 0.005 & -0.009 & 1 & -0.003 & 0.008 \\
\hline 3412 & 0.045 & 0.310 & 0.857 & 0.621 & -0.003 & 1 & 0.821 \\
\hline 4312 & 0.354 & 0.553 & 0.864 & 0.599 & 0.008 & 0.821 & 1 \\
\hline \multicolumn{8}{|c|}{ The correlation was evaluated by Pearson index, in which 1 stand for complete correlation and 0 stands for non-correlation. } \\
\hline \multicolumn{8}{|c|}{ Tab.6 correlation of samples of rural road } \\
\hline Correlation & 2134 & 2143 & \multicolumn{2}{|c|}{2341} & 2413 & 3412 & 4132 \\
\hline 2134 & 1 & 0.003 & \multicolumn{2}{|c|}{0.012} & 0.198 & 0.122 & 0.384 \\
\hline 2143 & \multirow{2}{*}{$\frac{0.003}{0.012}$} & 1 & \multicolumn{2}{|c|}{-0.028} & -0.014 & 0.150 & 0.626 \\
\hline 2341 & & -0.028 & \multicolumn{2}{|c|}{1} & -0.026 & -0.007 & 0.188 \\
\hline 2413 & 0.012 & -0.014 & \multicolumn{2}{|c|}{-0.026} & 1 & -0.003 & -0.002 \\
\hline 3412 & 0.122 & 0.150 & \multicolumn{2}{|c|}{-0.007} & -0.003 & 1 & 0.578 \\
\hline 4132 & 0.384 & 0.626 & & & -0.002 & 0.578 & 1 \\
\hline
\end{tabular}

\section{Conclusions}

In this test, the data of each MHHCM system has been collected, from which the difference among all samples was revealed. And it is concluded as follows.

(1) It is of great affection for operators, work condition to the result of the test. For example, when the work condition is better, the result is better and vise versa. A few of the samples even didn't finish some sections of the test.

(2) For the urban road test, variation coefficient varies from index to index. The $C_{v}$ of rut is $6.27 \%$, and for IRI is 8.94 , and for cracking is $6.87 \%$. All are above the standard $5 \%$.For the rural road test, the $C_{v}$ of rut is $7.78 \%$, and for IRI is 9.25 , and for cracking is $11.73 \%$. All are above the standard $5 \%$ as well.

(3) The correlation of all samples also varies from index to index. The correlation of IRI and rut are better than the cracking, which may be caused by different driving action of all operators. 


\section{Acknowledgments}

This work was financially supported by "Central Commonweal Organization Funding for Research (2017-9077)”.

\section{References}

[1] GB/T 26764-2011, Multifunctional High-speed Highway Condition Monitors.

[2] JTG/TE61 - 2014, Regulation Of The Automatic Test Of Condition Of The Pavement.

[3] JTG H20 - 2007, Standard Of Evaluation Of The Condition Of Pavement.

[4] JTG H10 - 2009, Regulation of Highway maintenance. 